California, 505 Parnassus Ave, San Francisco, CA 94143).

COMMENT. Seizure severity in term newborns with perinatal asphyxia can be associated with cerebral metabolic dysfunction and neuronal injury, independent of the structural damage detected by MRI. Previous studies using proton magnetic resonance spectroscopy have demonstrated that abnormalities of lactate and $\mathrm{N}$-acetylaspartate in newborns with perinatal asphyxia are risk factors for abnormal neurodevelopmental outcome (Ashwal et al. Ann Neurol 1997;41:470-481).

Brain damage markers. The release of glial protein S-100B from astrocytes into the peripheral circulation, due to abnormal membrane integrity, is used as a measure of brain damage. In patients with head trauma, the higher the S-100B serum concentration, the more severe the outcome and neurologic impairment. Other proteins used as markers of brain damage include glial fibrillary acidic protein (GFAP) and neuron-specific enolase (NSE). In the past, most of the studies involved measurement of serum S-100 after pediatric cardiac operations. Leviton A and Dammann O (Acta Paediatr 2002;91:9-13) advocate the use of these protein markers in addition to serum inflammatory cytokines in the evaluation of newborns at risk for brain damage. Blood lactate as a measure of tissue anoxia in neonates has limitations (Saugstad OD. Acta Paediatr 2002;91:17-19).

\title{
PERINATAL AND CHILDHOOD STROKE
}

The epidemiology, risk factors, outcome and prognosis of perinatal and childhood stroke were reviewed at a workshop sponsored by the National Institute of Neurological Disorders and Stroke in Bethesda, MD, on Sept 18 and 19, 2000. Neonatal stroke occurs in approximately $1 / 4000$ live births per year. Cause is often undetermined, but includes cardiac disorders, infection, blood abnormalities, and $<5 \%$ associated with birth asphyxia. Coagulation disorders (factor V Leiden and prothrombin mutation, protein $\mathrm{C}$, protein $\mathrm{S}$, and antithrombin III deficiences are identified in 50\% of infants and children with cerebral thromboembolism. Maternal factors may also contribute. An abnormal EEG during the first week after stroke is predictive of hemiplegia. Infarction demonstrated by neuroimaging and involving the internal capsule also predicts development of hemiplegia, whereas involvement of other regions is less predictive.

Childhood stroke incidence is estimated at 2-3/100,000 in the USA, and the US mortality rate attributed to stroke in children is $0.6 / 100,000$. Stroke mortality has ranged from $7 \%$ to $28 \%$. Causes include thromboembolism, arteriopathy, or are undetermined. Risk factors include cardiac disorders, coagulation disorders, sickle cell disease, infection, moyamoya, and arterial dissection. Up to $30 \%$ have postvaricella angiopathy. Sinus venous thrombosis occurs usually in the first year of life, and presents with focal abnormalities and seizures. Risk factors include head and neck infections, dehyration, perinatal complications, and coagulation disorders. Hemorrhagic stroke is less common than ischemic stroke in children. Risk factors include vascular malformation, malignancy, trauma, and coagulation disorders; AVM is the most common cause. The evaluation of stroke in children should include hematologic, metabolic, and angiographic studies. The Canadian Pediatric Stroke Registry (CPISR) outcome data, which includes 402 children with arterial ischemic stroke and 160 with sinus thrombosis, show that $27 \%$ are neurologically normal, $61 \%$ abnormal, $22 \%$ recurred, and a mortality of 12\%. (Lynch JK, Hirtz DG, DeVeber G, Nelson KB. Report of the National Institute of Neurological Disorders and Stroke workshop on perinatal and childhood stroke. 
Pediatrics Jan 2002;109:116-123). (Reprints: Dr JK Lynch, Bldg 10, Room 5S220 10 Center Dr, MSC 1447, Bethesda, MD 20892).

COMMENT. The authors conclude that pediatric stroke registries, similar to the one in Canada, are needed to provide data regarding the impact of maternal and perinatal factors on the causes and outcome of childhood stroke in the US.

\section{DEVELOPMENTAL DISORDERS}

\section{X-LINKED LISSENCEPHALY WITH ABSENT CORPUS CALLOSUM}

Three new cases of the congenital syndrome consisting of X-linked lissencephaly, absent corpus callosum, and genital anomalies (XLAG) are reported from the University Hospital, Angers, France. Male sex, intractable epilepsy, hypotonia, and early mortality are additional characteristics. MRI findings include anterior pachygyria, posterior agyria, thickened cerebral cortex, dysplastic basal gangiia, and agenesis of the corpus callosum. Pathologically, the brain shows a trilayered cortex, neuronal migration defect, dysplastic basal ganglia, and gliotic and spongy white matter. Females related to affected boys may be mentally retarded, suffer from epilepsy, and have agenesis of the corpus callosum. (Bonneau D, Toutain A, Laquerriere A, et al. X-linked lissencephaly with absent corpus callosum and ambiguous genitalia (XLAG): Clinical, magnetic resonance imaging, and neuropathological findings. Ann Neurol March 2002;51:340-349). (Respond: Dr Bonneau, Sevice de Genetique Medicale, CHU d'Angers, 4 rue Larrey, 49100 Angers, France).

COMMENT. First described by Berry-Kravis and Israel in 1994, XLAG is characterized by lissencephaly, complete agenesis of the corpus callosum, and hypogenitalism. A posterior agyria, an anterior pachygyria, and an intermediate thickening of the cortex distinguish this syndrome from lissencephaly type I, in which the cortex is thicker, and the corpus callosum may be hypoplastic but not absent. The MRI and neuropathological features are also distinct. Abnormal MRI findings in carrier females also expand the XLAG phenotype.

\section{MYELOMENINGOCELES AND INCIDENCE OF SHUNTING}

The distribution of postnatally repaired myelomengocele (MMC) lesions, characterized by neurologic and radiologic assessment, and the incidence of shunting were determined and correlated by a retrospective chart review of 297 patients followed at the spina bifida clinic at the Children's Hospital of Philadelphia. The rate of ventricular shunting was $81 \%$, and was correlated with the level of the lesion. The more cephalad the MMC, the higher the incidence of shunting. Levels determined by functional neurologic examination were generally higher or equal to the vertebral level of the lesion defined by spine radiographs. Sacral lesions categorized radiologically rather than neurologically had a higher shunt rate. (Rintoul NE, Sutton LN, Hubbard AM, et al. A new look at myelomeningoceles: Functional level, vertebral level, shunting, and the implications for fetal intervention. Pediatrics March 2002;109:409-413). (Reprints: Leslie N Sutton MD, Division of Neurosurgery, Children's Hospital of Philadelphia, 34th St and Civic Center Blvd, Philadelphia, PA 10194).

COMMENT. In this series of patients, the proportion of lumbar MMC was $62 \%$ in contrast to $80 \%$ reported by Emery and Lendon in a study published in 1973 . The authors of the Philadelphia study comment that differences in the 